\title{
Giant Sublingual Epidermoid Cyst
}

\author{
SA HOQUE ${ }^{\mathrm{a}}$, MM ISLAM $^{\mathrm{b}}$, MA RASHID $^{\mathrm{c}}$
}

\begin{abstract}
Summary:
Epidermoid and dermoid cysts represent less than $0.01 \%$ of all oral cavity cysts. The cysts can be defined as epidermoid when the lining presents only epithelium, dermoid cysts when skin adnexa are found, and teratoid cysts when other tissue such as muscle, cartilage, and bone are present.
\end{abstract}

In this article, we present a case of sublingual epidermoid cyst with a submental component in a 15 years old girl. She presented with complaints of a mass in the oral cavity, difficulty in speaking, dysphagia, progressive snoring during sleep, occasional shortness of breath and cosmetic problems for last

\section{Introduction:}

Dermoid cysts are classified as epidermoid, true dermoid \& teratoid cysts ${ }^{1,2}$. However the term "dermoid" is typically used to indicate all three categories ${ }^{3}$. Epidermoid cysts do not contain skin adnexal structure. True dermoid cysts contain skin adnexal structures such as hair, hair follicle, sweat gland \& sebaceous gland. Teratoid cysts contain all three embryological elements such as nails, brain , muscle ,glandular tissue. ${ }^{1,2,4}$.

Sex distribution is equal ${ }^{5}$. $7 \%$ of all dermoid cysts occur occurring in the head and neck area and 1.6\% within the oral cavity ${ }^{6}$. They represent less than $0.01 \%$ of all oral cavity cysts ${ }^{7}$.

They may reach a large size involving more than one anatomical area and/or abut the hyoid bone when in the neck ${ }^{8}$.Such a swelling on the floor of the mouth can occasionally cause serious problems for swallowing and speaking ${ }^{9,10}$.

The treatment of dermoid cysts is surgery by an intraoral or extraoral route according to the location and the size of the mass ${ }^{11}$.

a. Dr. Shameem Anwarul Hoque, FCPS (Otolaryngology), Associate Professor of Otolaryngology, Jalalabad Ragib Rabeya Medical College, Sylhet, Bangladesh.

b. Dr. Md. Mofakkarul Islam, DLO, Consultant,Otolaryngology, Jalalabad Ragib -Rabeya Medical College, Sylhet, Bangladesh.

c. Dr. M A Rashid, DA, Associate professor of Anesthesiology, Jalalabad Ragib -Rabeya Medical College, Sylhet, Bangladesh.

Address of Correspondence: Dr. Shameem Anwarul Hoque, 11, Housing Estate, Amborkhana, Sylhet 3100, Bangladesh, Mobile \#0171500254, Email: sahoque@gmail.com

Received: 9 May, 2012

Accepted: 21 November, 2012
6 months. A mass displacing the tongue superiorly and posteriorly was noticed in oral cavity and a firm diffuse swelling was also noticed in the submental area, extending down to the thyroid notch. The differential diagnosis includes infectious process, ranula, lymphatic malformation, tumours etc. FNAC revealed preoperative diagnosis of an epidermoid cyst . Under general anesthesia a submental horizontal incision was made and the mass was excised completely. Histopathological examination of the mass confirmed diagnosis of an epidermoid cyst.

(J Banagladesh Coll Phys Surg 2013; 31: 159-161)

\section{Case Report}

A 15 years old female from Bishwanath, Sylhet presented with the complaints of a mass in the oral cavity, difficulty in speaking, dysphagia, progressive snoring during sleep, occasional shortness of breath and cosmetic problems for the past 6 months. The swelling started insidiously, followed by a slow progression and attained a huge size. There was no history of previous surgery or trauma to the oral cavity or neck. On examination, there was a big sublingual mass with extension to sub mental region. Sublingual mass had normal covering mucosa displacing the tongue superiorly and posteriorly. A firm diffuse swelling was also noticed in the submental area, extending down to the thyroid notch giving the patient a double chin appearance. The swelling was non tender and firm in consistency. On pressure over tongue with glove finger swelling at submental area moved downward to increase in size. The swelling did not fluctuate, neither it did transilluminate. The regional lymph nodes was not palpable. FNAC of swelling made diagnosis of epidermoid cyst. She was advised excision of mass by extra oral route. Under general anesthesia with endotracheal intubation, the patient underwent surgical removal of the mass on 08.04.2012 at a private hospital at Sylhet , Bangladesh. A horizontal incision was made at sub mental area. Platysma was divided, muscles of floor of mouth were splitted and a giant cyst about $6.5 \mathrm{cmX} 3.5 \mathrm{cmX} 3 \mathrm{~cm}$ was dissected from the surrounding tissues and removed .Downward pressure over tongue by glove figure assisted dissection of mass. The wound was closed primarily. There was no intra- 
procedure complication. Proper haemostasis ensured. The postoperative period was without any complication and the tongue went back to its normal position. Histological examination of resected specimen confirmed the diagnosis of epidermoid cyst.
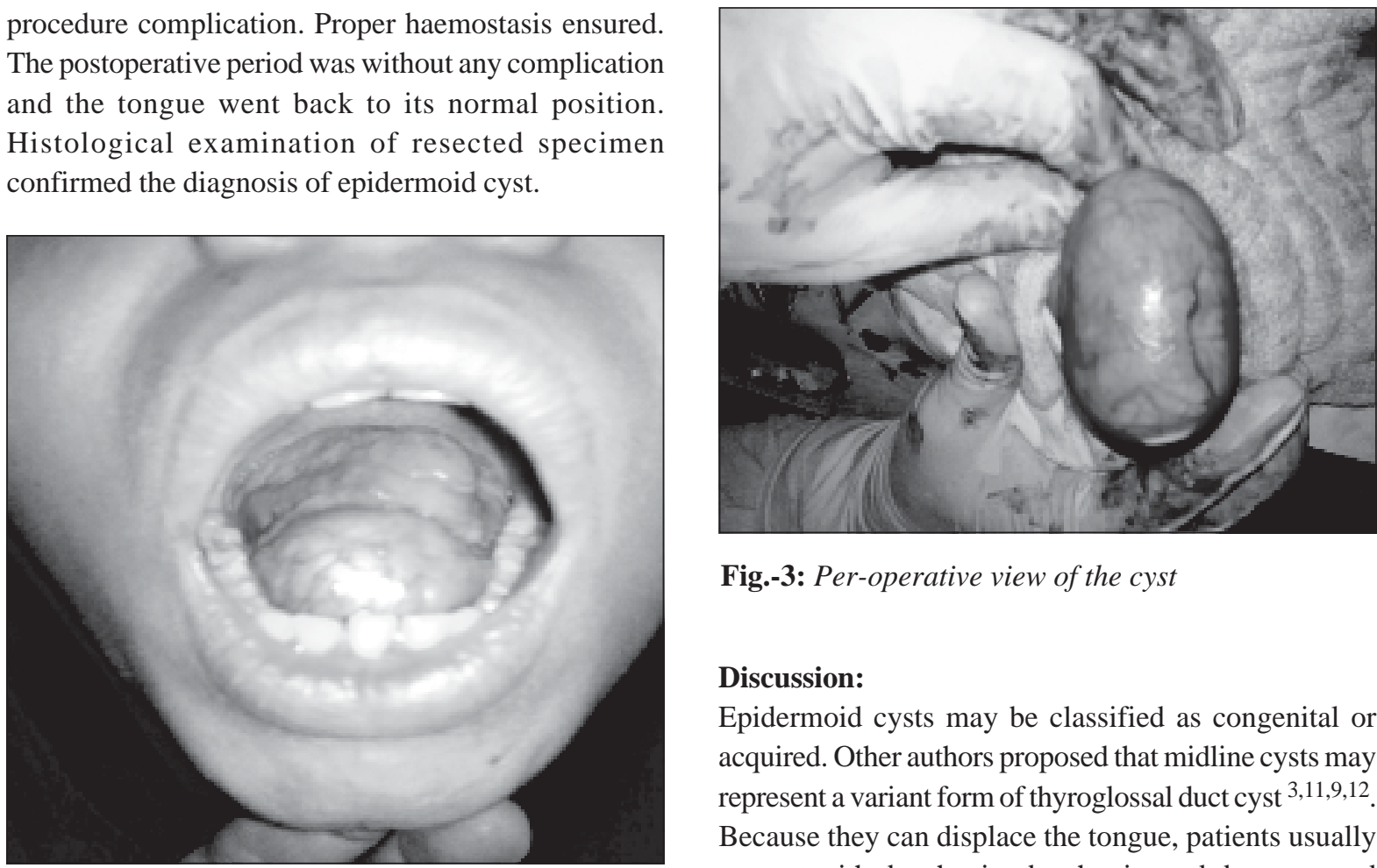

Fig.-3: Per-operative view of the cyst

\section{Discussion:}

Epidermoid cysts may be classified as congenital or acquired. Other authors proposed that midline cysts may represent a variant form of thyroglossal duct cyst $3,11,9,12$. Because they can displace the tongue, patients usually present with dysphagia, dysphonia, and dyspnea, and

Fig.-1: Swelling in sublingual region

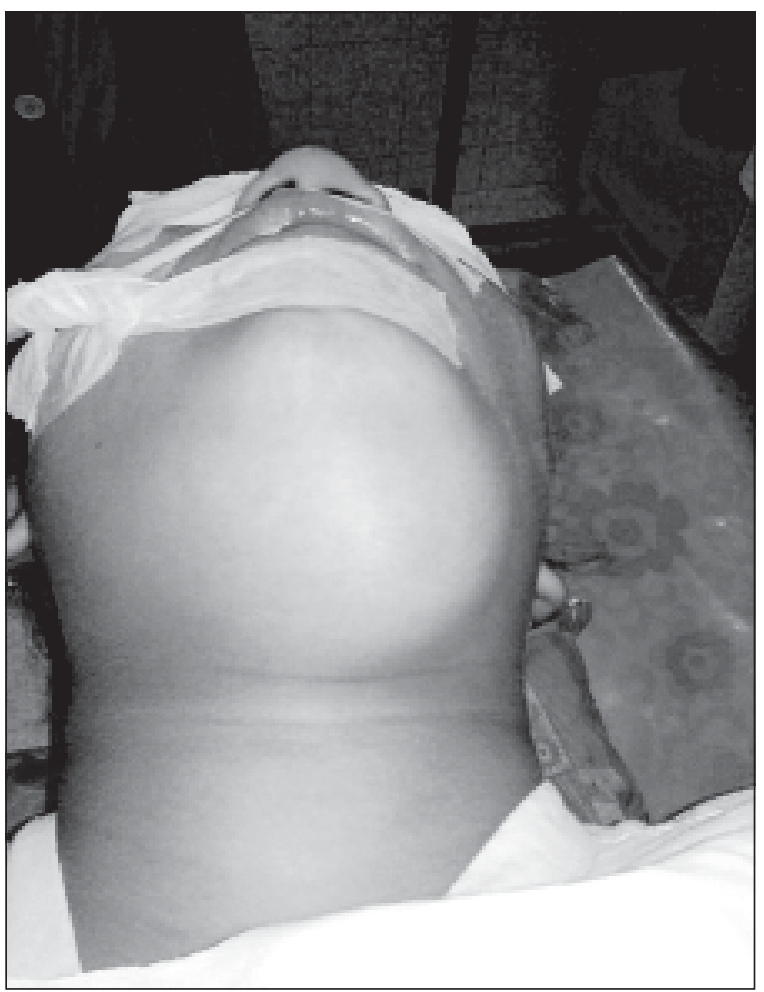

Fig.-2: Swelling at submental area (double chin) in the case of lower localization, they present a characteristic double chin ${ }^{11}$.

Dermoid cysts are generally diagnosed in young adults in the second and third decades of life ${ }^{11}$.

The differential diagnosis of sublingual lesions includes: infectious process, ranula, lymphatic malformation, dermoid cyst, epidermoid cyst, heterotopic gastrointestinal cyst and duplication foregut cyst. In these cases, it is necessary to use ultrasonography, FNAC, CT scan or magnetic resonance imaging ${ }^{9}$. Ultrasonography represents the first choice of imaging technique because it is reliable, economical, and without $\mathrm{x}$-ray exposure. CT scan and magnetic resonance imaging allow more precise localization of the lesion in relationship to geniohyoid and mylohyoid muscles, and enable the surgeon to choose the most appropriate surgical approach ${ }^{11}$.

Complete surgical excision is the only effective treatment and is usually straightforward ${ }^{4,5}$. Several techniques are reported in the literature, which may be divided into intraoral and/or extraoral approach ${ }^{8}$. The extraoral approach is generally preferred in the case very large sublingual cysts, whereas the intraoral approach is used for smaller sublingual cysts ${ }^{13}$. 
Malignant changes have been recorded in dermoid cysts by New and Erich but not in the floor of the mouth, although a $5 \%$ rate of malignant transformation of oral dermoid cysts of the teratoid type has been reported by other authors ${ }^{14}$.

Conclusion

Demoid cysts of floor of mouth may involve more than one anatomical area specially submental area and reach a large size. Such a swelling can occasionally cause serious problems for swallowing and speaking .FNAC and imaging are necessary in the preoperative diagnosis and selection of appropriate surgical approach. Complete surgical excision is the only effective treatment for these kinds of lesions. Prognosis is very good, with a very low incidence of relapse.

\section{References:}

1. Simo R \& Jeannnon J P. Benign neck disease, In: Watkinnson J C \& Gilbert R W, editor, Stell \& Maran’s Textbook of Head and neck surgery and oncology, $5^{\text {th }}$ ed, Hodder Arnold, 2012 : 218-219.

2. Calderon S, Kaplan I. Concomitant sublingual and submental epidermoid cysts: a case report. J Oral Maxillofac Surg. 1993;51:790-792.

3. Howell CJT. The sublingual dermoid cyst: Report of five cases and review of the literature. Oral Surg Oral Med Oral Pathol. 1985;59:578. doi: 10.1016/0030-4220(85)90184-7.

4. Lin D T \& Deschler D G . Neck masses, In: Lalwani A K editor, Current diagnosis \& treatment otolaryngology - Head \& Neck Surgery, ${ }^{\text {nd }}$ ed, McGraw Hill Medical, 2008:402.
5. Clarke P. Benign neck disease: infections and swellings, In : Gleeon M, editor, Scott-Brown's Otorhinolaryngology, Head and neck Surgery, $7^{\text {th }}$ ed,volume 2, Hodder Arnold, 2008: 1782.

6. Turetschek K, Hospodka H, Steiner E. Case report: epidermoid cyst of the floor of the mouth: diagnostic imaging by sonography, computed tomography and magnetic resonance imaging. Br J Radiol. 1995;68:205-207.

7. Rajayogeswaran V, Eveson JW. Epidermoid cyst of the buccal mucosa. Oral Surg Oral Med Oral Pathol. 1989;67:181-184. doi: 10.1016/0030-4220(89)90326-5.

8. Bitar MA, Kumar S. Plunging congenital epidermoid cyst of the oral cavity. Eur Arch Otorhinolaryngol. 2003;260: $223-225$.

9. Walstad WR, Solomon JM, Schow SR, Ochs MW. Midline cystic lesion of the floor of the mouth. J Oral Maxillofac Surg. 1998;56:70-74.

10. Koca H, Seckin T, Sipahi A, Kazanc A. Epidermoid cyst in the floor of the mouth: Report of a case. Quintessence Int. 2007;38:473-477.

11. Longo F, Maremonti P, Mangone GM, De Maria G, Califano L. Midline (dermoid) cysts of the floor of the mouth: report of 16 cases and review of surgical techniques. Plast Reconstr Surg. 2003;112:1560-1565.

12. De Ponte FS, Brunelli A, Marchetti E, Bottini DJ. Sublingual epidermoid cyst. J Craniofac Surg. 2002;13:308-310.

13. Lowry RE, Tempero RM, Davis LF. Epidermoid cyst of the floor of the mouth. J Oral Surg. 1979;37:271.

14. Zachariades N, Skoura-Kafoussia C. A life threatening epidermoid cyst of the floor of the mouth: Report of a case. J Oral Maxillofac Surg. 1990;48:400. 